\title{
TECNOLOGIAS DISRUPTIVAS: 0 CASO DO UBER
}

\author{
DISRUPTIVE TECHNOLOGIES: THE UBER CASE
}

Recebido em 21.09.2017. Aprovado em 14.11.2017

Avaliado pelo sistema double blind review

DOI: http://dx.doi.org/10.12712/rpca.v11i5.1078

\section{Paulo Henrique Souto Maior Serrano}

Universidade Federal da Paraíba (UFPB), João Pessoa/PB, BRASIL

paulohsms@gmail.com

\section{Renata Francisco Baldanza}

Universidade Federal da Paraíba (UFPB), João Pessoa/PB, BRASIL

renatabaldanza@gmail.com

\section{Resumo}

As tecnologias estão presentes nos processos e dinâmicas sociais e redesenham seu contexto em diversos âmbitos. Estas são alvo dos mais diversos sentimentos como euforia, receio, resistência ou adoção indiscriminada. Quando algo novo adentra o contexto social, de algum modo o reconfigura. Assim também têm sido as atuais tecnologias disponíveis nos smartphones. O Uber, serviço de transporte particular, repulsa taxistas e atrai consumidores. Este ensaio verifica a existência de relações entre os fenômenos precedentes observados por autores como Schumpeter e Christensen, e que foram representados no processo de formulação de suas teorias com a empresa Uber. Características capazes de classificar o modelo de negócios do Uber como uma "nova combinação" (SCHUMPETER, 1997) foram identificadas. Os direcionamentos tomados por essa indústria são discutidos neste ensaio através da distinção entre "tecnologias de sustentação", utilizadas pelos táxis e “inovações disruptivas", praticadas pelo Uber.

Palavras-chave: Inovação Disruptiva. Destruição Criativa. Tecnologias de Sustentação. Uber.

\begin{abstract}
Technologies are present into processes and social dinamics and redesign its contexts in various scopes. Target of feelings like euphoria, fear, resistence or indiscriminate adoption. When something new enters the social context, it somehow reconfigures it, so does the technologies available on smartphones. Uber, a private transportation service, uprises taxi drivers and attracts consumers. This assay aims to verify the existence of relations between the preceding phenomena observed by authors like Schumpeter and Christensen, that were presented on the formulation process of his theories, with Uber's organization. Characteristics able to classify Uber's business model as a "new combination" (SCHUMPETER 1997) were identified. The directions taken by this industry are discussed in this assay through the distinction between "support technologies" used by taxis and "disruptive innovation", practiced by Uber.
\end{abstract}

Keywords: Disruptive innovation. Creative destruction. Support technologies. Uber. 


\section{Introdução}

Utilizando-se dos conceitos, teorias e sistematizações fundamentadas na observação empírica do economista Joseph Schumpeter $(1997,2003)$ e dos desdobramentos e novas teorias estabelecidas pelo professor Clayton Christensen (1997, 2003), este ensaio, de cunho teórico-reflexivo, explora a experiência de inovação proporcionada pela implementação da solução de transporte individual de passageiros desenvolvida pela empresa Uber.

O recorte estabelecido concentra-se na perspectiva do mercado emergente e preexistente do transporte de passageiros. Objetiva-se aqui, verificar a existência de relações entre os fenômenos precedentes observados pelos autores supracitados e representados no processo de formulação de suas teorias com o fenômeno provocado pelo aplicativo Uber. Para tanto, estruturou-se este ensaio de modo a, primeiro, apresentar os principais marcos teóricos de suporte à análise reflexiva posterior. Segundo, uma sessão cujas relações, análise crítico-reflexivas e demais considerações sobre a aproximação entre o Uber e as teorias supracitadas são abordadas e desenvolvidas.

A sequência de conteúdos que estrutura este trabalho inicia-se pela apresentação das teorias que o fundamentam. A compreensão do ciclo econômico, as novas combinações como motores do desenvolvimento e o conceito de destruição criativa são as principais contribuições de Schumpeter, explicadas na seção "Teoria do desenvolvimento econômico".

A seção "Tecnologias ou inovações disruptivas" apresenta os fundamentos teóricos de Christensen para a compreensão dos motivos pelos quais as organizações fracassam, introduzindo o conceito de tecnologia de sustentação e tecnologia disruptiva.

Na sequência, "Uber, a empresa aplicativo" apresenta um breve histórico sobre o Uber e explicações sobre o processo de criação de valor para seus consumidores. A seção "As novas combinações do Uber" explora a relação das constatações apresentadas na teoria de Schumpeter $(1997,2003)$ com as observações empíricas do fenômeno provocado pela empresa Uber.

Utilizando o aporte teórico de Christensen (1997, 2003), a seção "A falha dos táxis" justifica e aponta algumas constatações sobre os motivos pelos quais a indústria dos táxis pode sofrer prejuízos financeiros com o surgimento do Uber.

A pesquisa aponta em suas "Considerações finais" as características da empresa Uber capazes de promover a destruição criativa no mercado de transporte público individual remunerado de passageiros relacionando-as com o contexto brasileiro e, ainda, os direcionamentos tomados pela indústria dos táxis que podem contribuir para o seu fracasso.

\section{Teoria do desenvolvimento econômico}

O economista austro-húngaro Joseph Schumpeter defendia a integração da economia com a sociologia para o melhor entendimento das teorias econômicas. A compreensão matemática, dominante na época, não se apresentaria como suficiente para o entendimento da complexidade econômica.

O ciclo econômico de Schumpeter foi detalhado em "A Teoria do Desenvolvimento Econômico: Uma Investigação sobre Lucros, Capital, Crédito, Juro e o Ciclo Econômico" de 1911. Esse período entre o fim do século XIX e começo do século XX foi marcado pela invenção da lâmpada, o automóvel e o telefone, soluções que se tornaram essenciais para as grandes mudanças no cenário político mundial, com o fortalecimento dos Estados Unidos como potência econômica. É nesse contexto de mudança que Schumpeter formula a sua compreensão do ciclo econômico.

A princípio, a economia é entendida em um estado de equilíbrio, cada oferta encontra sua demanda, todas as transações comerciais estariam sendo atendidas e, no período de consumo seguinte, esse processo iria se repetir. O sistema econômico não se modifica por si só.

Podemos imaginar que, ao fim do período econômico, os produtos de todos os indivíduos formam em certo lugar uma pilha que é então distribuída segundo certos princípios. Como não acarreta nenhuma mudança essencial dos fatos, a suposição é bastante admissível até esse ponto. Podemos então dizer que cada indivíduo lança sua contribuição nesse grande reservatório social e posteriormente recebe algo dele. A cada contribuição corresponde em algum ponto do sistema uma reivindicação de outro indivíduo; a cota de cada um está disponível em algum lugar. (SCHUMPETER, 1997, p. 28) 
A estabilidade prevista nesse modelo de fluxo circular contínuo e constante estende-se também aos valores. Schumpeter (1997) entende que os valores são construídos a partir de uma inter-relação entre o indivíduo e a sociedade em que um influencia e é influenciado pelo outro. Os preços não expressariam o valor social de um produto ou serviço "mas apenas o resultado de processos que atuam sob a pressão de muitas valorações individuais" (Schumpeter, 1997, p. 67). Reconhecendo que podem haver vários motivos para o consumo, Schumpeter sintetiza a atividade econômica como um processo de satisfação de necessidades.

Mas o equilíbrio previsto no modelo tradicional apontado por Schumpeter é rompido pelo fenômeno do desenvolvimento econômico que caracteriza-se essencialmente pela mudança e pela inovação.

As inovações no sistema econômico não aparecem, via de regra, de tal maneira que primeiramente as novas necessidades surgem espontaneamente nos consumidores e então o aparato produtivo se modifica sob sua pressão. Não negamos a presença desse nexo. Entretanto, é o produtor que, via de regra, inicia a mudança econômica, e os consumidores são educados por ele, se necessário; são, por assim dizer, ensinados a querer coisas novas, ou coisas que diferem em um aspecto ou outro daquelas que tinham o hábito de usar. (SCHUMPETER, 1997, p. 76)

O principal motor do desenvolvimento econômico é a inovação ou as "novas combinações" que se realizam, de acordo com Schumpeter (1997, p. 76). O autor destaca cinco casos distintos: 1) Introdução de um novo bem ou uma nova qualidade de um bem; 2) Introdução de um novo método de produção ou comercialização; 3) Abertura de um novo mercado; 4) Conquista de uma nova fonte de oferta de matériaprima; 5) Estabelecimento de uma nova organização em uma indústria, como a criação de um monopólio, ou a fragmentação de uma posição de monopólio.

Ser detentor dos meios de produção e dispor de crédito são os requerimentos para a concretização de algum dos cinco casos expostos. É importante destacar que os meios produtivos existem dentro do próprio fluxo econômico vigente e são acrescentados pelas iniciativas de desenvolvimento que se somam a esse fluxo. A inovação é condicionada pelo compartilhamento do conhecimento e condições de produção anteriores. Assim tem-se a dinâmica do
Nanos gigantum humeris insidentes - só se enxerga mais longe por estar no ombro de gigantes.

A mudança provocada pela introdução de um novo valor ou de uma nova necessidade no fluxo circular da economia cria a instabilidade e o consequente movimento posterior de busca do equilíbrio. A inovação é copiada ou reproduzida de forma semelhante e o equilíbrio é reestabelecido até que uma outra nova combinação de tecnologias ou modo de produção seja criada, reiniciando o ciclo. As organizações que perdem a sua fatia do mercado nesse processo podem encerrar suas atividades, manter-se em um mercado menor dividido com a organização inovadora, ou alterar o seu campo de atuação.

$\mathrm{Na}$ obra "Capitalismo, Socialismo e Democracia" de 1944, Schumpeter apresenta a compreensão do capitalismo como sendo por natureza uma forma de mudança econômica que nunca poderá ser estacionária. Isso não se dá apenas pelo fato da vida econômica acontecer em um ambiente social e natural que muda. Esses fatores são importantes e as mudanças provocadas por guerras ou revoluções com frequência condicionam a mudança. "The fundamental impulse that sets and keeps the capitalist engine in motion comes from the new consumers' goods, the new methods of production or transportation, the new markets, the new forms of industrial organization that capitalist enterprise creates". (SCHUMPETER, 2003, p. 82)

Esse impulso de mudança que revoluciona a economia, destruindo a estrutura antiga e criando novos modelos, é o que Schumpeter chama de destruição criativa ou destruição criadora. Para ilustrar o processo de mutação industrial, cita a evolução da produção de energia por rodas d'águas para a usina de energia moderna, as carruagens que serviam de correio evoluindo para os trens e aviões posteriormente.

Diante de seus pensamentos, alguns autores neo-schumpeterianos trouxeram abordagens complementares e/ou críticas às reflexões contidas nas obras do Schumpeter. Rosenberg (1969; 1982), por exemplo, destacou que no processo dinâmico do desenvolvimento tecnológico, certos desajustes e desequilíbrios são fundamentais para que uma mudança técnica, de fato, alavanque o crescimento econômico. É certo, afirma o autor, que estes criam pontos que chamam a atenção dos pares para a solução dos problemas advindos deste novo contexto. 
Ainda direcionando à análise de Schumpeter, Nelson e Winter (1982) complementaram que a concorrência nos moldes schumpeterianos decerto produz vencedores e perdedores, o que ocasionaria um cenário em que algumas organizações conseguiriam tirar maior proveito das oportunidades técnicas em detrimento a outras. Como um ciclo vicioso, as que conseguem maior êxito com as técnicas avançam no mercado e, como consequência, as demais caem cada vez mais vertiginosamente.

Uma forte crítica à teoria de Schumpeter recaí sobre o diagnóstico da decadência do capitalismo, já que todo período de desenvolvimento econômico é seguido de recessão econômica em que há estagnação e reequilíbrio do ciclo econômico através da inflação e do aumento do consumo. O ponto de reequilíbrio é maior do que foi no período de recessão econômica anterior, fazendo com que exista a necessidade de aumentar o volume de dinheiro até um ponto em que há a destruição da estrutura da sociedade capitalista.

Outras críticas são listadas por Susan e Chandradas (2012), dentre as quais destaca-se o fato de Schumpeter basear todo o processo da sua teoria na figura do inovador, que pode se apresentar como uma figura muito idealizada.

Independente das críticas acerca da teoria de Schumpeter, a explicação sobre o ciclo econômico, o conceito de destruição criativa e as novas combinações como motores do desenvolvimento são contribuições relevantes para a compreensão da inovação dentro de uma lógica de valores, mercado e consumo.

\section{As tecnologias ou inovações disruptivas}

As contribuições de Schumpeter influenciaram as pesquisas do professor de administração Clayton Christensen na redação do livro "O Dilema da Inovação - quando as novas tecnologias levam empresas ao fracasso", de 1997. O dilema em questão refere-se às decisões lógicas e coerentes que são fundamentais para o sucesso da organização, mas que também são a razão por trás da perda de posições de liderança.

Três constatações foram descobertas por Christensen para caracterizar os direcionamentos de organizações que fracassam: 1) o investimento em tecnologias de sustentação ao invés das tecnologias disruptivas; 2) a falta de observação de que as tecnologias podem avançar mais rápido que a demanda do mercado; 3) o entendimento de que o investimento em tecnologias disruptivas não é uma decisão financeira racional.

As tecnologias de sustentação são aquelas cujos produtos ou serviços já estabelecidos precisam para baixar seu custo e aumentar a sua qualidade, uma inovação na própria arquitetura do produto ou serviço. As mudanças provocadas por essas tecnologias afetam os consumidores já existentes e ajudam a sustentar as trajetórias já estabelecidas das organizações. Esse tipo de tecnologia surge a partir de um processo de inovação evolucionário.

O conceito de tecnologias disruptivas estaria mais associado a um processo de inovação revolucionária, pela introdução no mercado de novos produtos ou serviços com melhores características ou menor custo para o consumidor.

Disruptive technologies bring to a market a very different value proposition than had been available previously. Generally, disruptive technologies underperform established products in mainstream markets. But they have other features that a few fringe (and generally new) customers value. Products based on disruptive technologies are typically cheaper, simpler, smaller, and, frequently, more convenient to use (CHRISTENSEN, 1997, p. 11).

É importante observar que a evolução dos conceitos que envolvem os fenômenos desta natureza discorreu de forma gradativa e os mesmos foram se moldando com o avançar dos estudos, iniciando-se com os pressupostos de Schumpeter em meados de 1942 e reconfigurando-se na obra de Christensen por volta de 1992 e posteriores, conforme sistematizado por $\mathrm{Yu}$ e Hang (2010, p. 436) na figura 1. 
Figura 1. Timeline da evolução da Teoria da Inovação Disruptiva

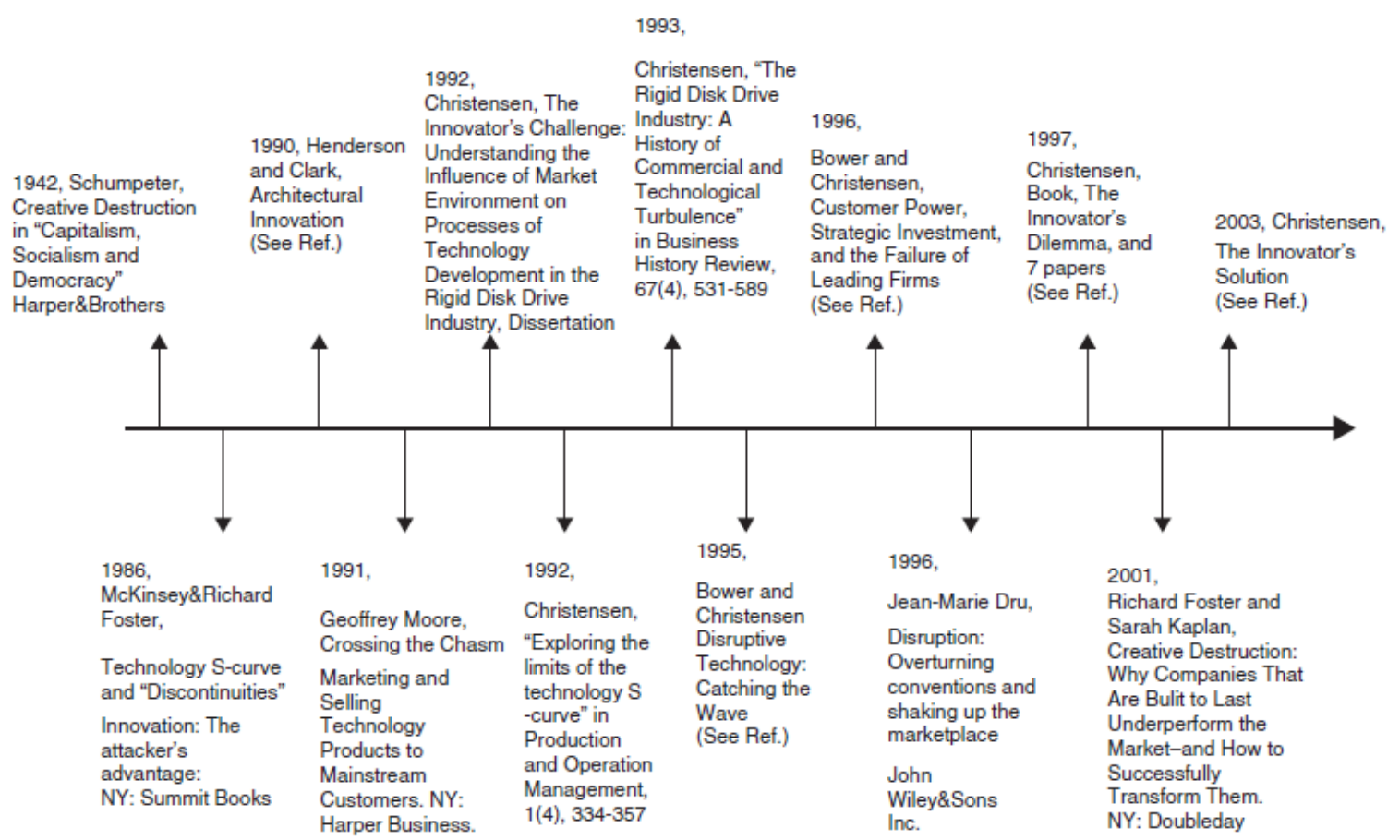

Fonte: Yu e Hang (2010)

Tais obras possibilitaram não somente um discurso mais adequado à nova realidade econômica, mercadológica e tecnológica, como também fizeram com que outros teóricos avançassem em suas observações empíricas. Não obstante, o próprio Christensen - um dos principais autores que deram continuidade ao debate nesta vertente - obteve, com o passar do tempo, maior robustez às suas reflexões acerca da teoria.

De acordo com a primeira observação de Christensen ao direcionar os seus recursos de pesquisa para o desenvolvimento de tecnologias de sustentação, a organização melhora o seu serviço, mas esquece da possibilidade de criar novos mercados ou do surgimento de soluções muito mais inovadoras e capazes de resolver a necessidade do consumidor com maiores benefícios, como mais conforto ou menor custo.

$\mathrm{Na}$ segunda descoberta, entende-se que a intensificação das pesquisas para dispor de melhores produtos em relação aos competidores ou para atingir melhores margens acaba por oferecer ao consumidor mais do que ele precisa ou está disposto a pagar. O progresso da tecnologia de sustentação aparece depois e vai além do que a faixa mais alta do mercado demanda. No caso da tecnologia disruptiva, a demanda por melhorias aparece na faixa mais baixa do mercado depois do progresso da tecnologia, o que faz com que a demanda seja atendida na hora certa. Nesta direção, Adner (2002) destaca que as tecnologias disruptivas deslocam a tecnologia convencional do fluxo principal do mercado. O exemplo apresentado por Christensen (1997, p. 94) ajuda a entender essa constatação:

IBM, the industry's first leader, sold its mainframe computers to the central accounting and data processing departments of large organizations. The emergence of the minicomputer represented a disruptive technology to IBM and its competitors. [...] IBM ultimately introduced its own line of minicomputers, but it did so primarily as a defensive measure, when the capabilities of minicomputers had advanced to the point that they were performance-competitive with the computing needs of some of IBM's customers.

Consumidores que um dia precisaram de computadores mainframe para os seus requerimentos de processamento de dados, por exemplo, não precisam mais comprá-los. A performance e o consequente custo dos mainframes excedem as necessidades dos consumidores. A tecnologia de sustentação melhorou tanto o produto que ele 
tornou-se desnecessário para a faixa inferior do mercado, que passou a consumir os computadores desktop mais baratos que também atendiam a demanda.

O investimento em tecnologias disruptivas, como listado por Christensen em sua terceira constatação, não é compreendido como um bom investimento porque essas tecnologias são normalmente mais simples e baratas, geralmente produzem pouco lucro, margens mais baixas e são comercializadas em mercados emergentes ou insignificantes. Os consumidores mais lucrativos geralmente não podem ou não querem usar produtos ou serviços baseados em tecnologias disruptivas, de acordo com o autor. As práticas mais comum em organizações de ouvir os consumidores mais lucrativos, identificar novas soluções em busca de mais lucro e crescimento, raramente são capazes de provocar o investimento em tecnologias disruptivas.

Christensen assume a importância da estratégia do modelo de negócio inovador na criação da disrupção. A tecnologia criaria condições para um impacto disruptivo, mas poucas tecnologias são disruptivas por si só. As decisões gerenciais em um nível político e cultural garantiriam o impacto necessário para caracterizar a tecnologia como disruptiva. O termo "inovação disruptiva" é utilizado para compreender também os contextos gerenciais e humanos que envolvem a aceitação das tecnologias inovadoras.

\section{UBER, a empresa aplicativo}

Criada em 2009 por Travis Kalanick e Garrett Camp em São Francisco, a empresa Uber utiliza um aplicativo móvel para conectar passageiros com motoristas que transportam pessoas em troca de uma remuneração financeira.

A Uber segue o modelo tradicional de pagar uma empresa para transportar um indivíduo de um ponto A para um ponto B. Assemelha-se ao serviço oferecido pelos taxistas, embora alguns o classifiquem como um serviço de carona paga, podendo os motoristas do Uber usar seus veículos pessoais para transportar os passageiros.

A solicitação de motoristas é feita diretamente pelo aplicativo utilizando os serviços de geolocalização e conexão móvel dos smartphones. A Uber divide em categorias os tipos de veículo e a base tarifaria que o consumidor desejar. O serviço mais utilizado é o
UberX, com menor custo e veículos que não são considerados de luxo. Como opção intermediária, tem-se Uber Select, onde os carros são de maior conforto. A opção Black Car é mais luxuosa e solicita um carro sedan preto, com bancos de couro e mais conforto. O SUV fornece um veículo maior com capacidade, para até 6 pessoas, dentre outros tipos como Uber Bag e Uber Pool, que permite dividir a corrida com outros passageiros desconhecidos que estão no mesmo percurso. Há ainda variações do serviço para o propósito de entrega de encomendas como UberEATS que oferece a possibilidade do parceiro realizar a entrega de comida com a sua bicicleta.

O processo de cobrança é feito por intermédio do próprio aplicativo, que através dos recursos de GPS e estimativas de tempo do percurso consegue, antes da solicitação, indicar uma previsão de qual será o valor cobrado, já que não há uma tarifa fixa. O pagamento é feito no aplicativo através do cartão de crédito cadastrado pelo consumidor. A empresa Uber fica com $20 \%$ do total cobrado e repassa $80 \%$ desse valor para o motorista. Atualmente aplica-se ainda o preço dinâmico, que se altera para mais ou para menos, de acordo com a demanda do momento para os percursos mais ou menos solicitados.

No Brasil a Uber funciona em várias cidades, provocando insatisfação e revolta de alguns motoristas de táxi, conforme documentado pela imprensa (GOOGLE, 2017). Os taxistas argumentam que tratase de um transporte ilegal de passageiros e que a falta de regulamentação, que isenta os motoristas do Uber de impostos, é uma concorrência desleal. A Uber funciona sob efeito de decisões liminares em algumas cidades do Brasil e em outras já foi proibido antes mesmo de começar a funcionar.

Os taxistas ou proprietários de licenças de táxis, também conhecidas como praças, afirmam que a Uber atua diretamente no seu mercado. Já a empresa Uber aponta o mercado de veículos particulares como o seu principal concorrente.

\section{As novas combinações do UBER}

Novas combinações ou inovações, de acordo com Schumpeter, que caracterizam o desenvolvimento econômico, podem ser identificadas no percurso 
de crescimento realizado pela empresa Uber. O movimento contrário, que busca impedir esse desenvolvimento observado na imprensa, caracteriza a instabilidade prevista por Schumpeter, na busca por um novo equilíbrio no fluxo econômico.

O surgimento da nova qualidade de um bem ou de um serviço - primeiro caso de combinação para o desenvolvimento econômico - pode ser identificado no modelo de negócios da Uber através das opções de escolha do veículo que realizará o transporte. A personalização do serviço, de acordo com o tipo de carro e o conforto desejado pelo consumidor, é uma característica distinta do que já existia no mercado.

Os carros categorizados como Uber Black distinguemse pelo conforto e suntuosidade. São carros pretos, sedan, com bancos de couro, motoristas bem vestidos que tratam com polidez o consumidor. Em todas as opções de transporte oferecidas os motoristas são orientados a oferecer água, balinhas, cortesia e discrição no transporte dos passageiros. A empresa Uber estabelece assim uma nova qualidade para os seus serviços.

A introdução de um novo método de produção ou comercialização - segundo item da lista de novas combinações de Schumpeter - pode ser entendido como uma inovação da empresa Uber. Em 2009 a comercialização dos serviços de transporte de passageiros por meio de aplicativos de smatphones era algo novo. É possível que desenvolvedores independentes ou empresas de desenvolvimento de software possam ter oferecido serviços de transporte por smartphone antes do Uber. Esta peculiaridade impossibilita a identificação da data de criação de um aplicativo por meio dos registros de fundação das empresas que os criam.

Mesmo diante da impossibilidade de assegurar o pioneirismo do Uber na utilização de aplicativos para smartphones, é possível verificar na tabela 1 que as empresas que utilizam os aplicativos para táxis ou caronas mais populares no mundo surgiram em 2009 ou poucos anos depois, o que coloca a Uber entre as primeiras a utilizar o aplicativo como método de comercialização deste serviço.
Tabela 1. Aplicativos para transporte de passageiros e suas respectivas datas de lançamento

\begin{tabular}{|c|c|}
\hline $\begin{array}{c}\text { Nome da } \\
\text { Companhia }\end{array}$ & Ano de Lançamento \\
\hline Uber & Março de 2009 \\
\hline Mytaxi & Junho de 2009 \\
\hline Flywheel & 2009 \\
\hline Gettaxi & 2010 \\
\hline Ola Cabs & 2010 \\
\hline Drivr & 2010 \\
\hline TaxiNow & 2010 \\
\hline SideCar & 2011 \\
\hline Kabbee & 2011 \\
\hline Hailo & 2011 \\
\hline EasyTaxi & 2011 \\
\hline Lyft & 2012 \\
\hline TaxiMe & 2012 \\
\hline Taxi 24/7 & 2012 \\
\hline JumpIn & 2012 \\
\hline 99Taxis & 2013 \\
\hline TaxiOnMobile & 2014 \\
\hline
\end{tabular}

Fonte: Sites das Empresas (2017)

A abertura de um novo mercado é identificada por Schumpeter como a terceira possível combinação para o processo de destruição criativa das soluções preexistentes. A constatação de que o Uber promoveu a abertura de um novo mercado foi observada no artigo publicado pelo Conselho Administrativo de Defesa Econômica (CADE), datado de dezembro de 2015, "Rivalidade após entrada: o impacto imediato do aplicativo Uber sobre as corridas de táxi porta-aporta” escrito por Luiz Alberto Esteves.

Esteves (2015) avaliou o impacto econômico imediato da entrada do Uber nas cidades de São Paulo, Rio de Janeiro, Belo Horizonte e Brasília. Utilizou para tanto, os dados de corridas em dois aplicativos de táxi durante 31 dias em 2014 e os mesmos dados por 31 dias em 2015, depois da entrada do Uber. Como grupo de controle, observou Porto Alegre e Recife, cidades em que o Uber não havia ainda atuado.

Os resultados obtidos não fornecem qualquer evidência de que o número de corridas de táxis contratadas nos municípios do grupo de tratamento (com presença do aplicativo Uber no período Depois 
da Entrada) tenham apresentado desempenho inferior aos do grupo de controle (sem presença do aplicativo Uber no período Depois da Entrada). Em termos de exercícios empíricos aplicados à política antitruste, isso significa que não podemos sequer assumir (ao menos nos períodos aqui analisados) a hipótese de que os serviços prestados pelo aplicativo Uber estivessem (até maio de 2015) no mesmo mercado relevante dos serviços prestados pelos aplicativos de corridas de táxis 99taxis e Easy Taxi. (ESTEVES, 2015, p. 24)

$\mathrm{Na}$ teoria de Schumpeter, o mercado anterior à inovação encontra-se bem posicionado, é lucrativo, não tem grandes quedas nem grandes crescimentos e geralmente assume uma posição de monopólio, o que representa uma fonte de investimentos mais segura. Esse mercado não desaparece instantaneamente.

Em um momento inicial, o novo mercado não é tão lucrativo pois depende de investimentos, mas tem grande potencial de crescimento e de retorno financeiro. Com o passar do tempo o novo mercado cresce e o mercado antigo diminui ao ponto de precisar se adaptar ou ser destruído. A utilização das tecnologias móveis como um novo método de comercialização do transporte de passageiros caracteriza a adaptação do mercado de táxis.

Para Schumpeter (2003), a mudança que provoca a instabilidade no fluxo circular da economia é copiada e com o passar do tempo o equilíbrio é reestabelecido. Essa reprodução das características inovadoras do Uber pode ser observada na tabela 1 pela quantidade de aplicativos de transporte de passageiros que surgiram depois de 2009.

O quarto item catalisador das mudanças é a conquista de uma nova fonte de oferta de matéria-prima. Como a categorização de Schumpeter está sendo relacionada a um serviço, a matéria-prima é entendida aqui como o principal elemento utilizado em um serviço de transporte: o veículo.

Os veículos utilizados para o transporte dos passageiros na Uber não são de propriedade da empresa. Os veículos de sua frota são dos próprios motoristas cadastrados para oferecer o serviço. Em um processo de recrutamento simplificado, a empresa Uber verifica as exigências do veículo e através do compartilhamento de documentos faz uma verificação no histórico do motorista. Um código de conduta é enviado e o motorista estará pronto para dirigir.
O que torna a experiência Uber realmente excelente são as pessoas atrás do volante. Elas são pais e mães. Alunos e professores. Veteranos. Vizinhos. Amigos. Nossos parceiros dirigem seus próprios carros (em seus próprios horários) em cidades pequenas e grandes. Por isso, mais de um milhão de pessoas em todo o mundo se inscreveram para dirigir. (UBER, 2016)

Ao se comprometer com a segurança do passageiro e do motorista por meio de sistema de avaliação - seguro completo; equipe de resposta a incidentes; triagem dos motoristas; mecanismo de compartilhamento de rota - a Uber consegue receber a oferta de matériaprima de muitas fontes diferentes.

O quinto item definido por Schumpeter identifica como motor do desenvolvimento econômico alavanca o estabelecimento de uma nova organização em uma indústria que poderia se materializar por meio da criação ou da fragmentação de um monopólio. Devido a regulamentação governamental, o serviço de transportes de pessoas nas grandes cidades é restrito aos veículos autorizados com alvarás.

Para se tornar um taxista, o indivíduo precisa se inscrever em uma lista de espera para a distribuição de novas licenças, alugar os veículos de motoristas ou cooperativas ou comprar uma licença já existente de um taxista proprietário desta. As licenças autorizam o taxista a estacionar o carro em um lugar específico para aguardar os passageiros e atuar nessa área. Os locais mais movimentados são vendidos por um preço mais alto. Com o surgimento da Uber, o mercado de venda de licenças ou medallions nos Estados Unidos está parado e os preços dessas licenças começaram a baixar (BARRO, 2015).

O mercado é restrito aos taxistas que possuem alvarás, caracterizando um monopólio que, com a popularização do aplicativo Uber e de outros aplicativos semelhantes como o Lyft, passa a ser fragmentado.

\section{O problema dos taxistas}

Através das investigações de Christensen (1997) sobre o surgimento de novas tecnologias como circunstância capaz de levar empresas à falência, é possível identificar características de decisões equivocadas em alguns direcionamentos tomados pelos taxistas. 
A primeira característica é o investimento em tecnologias de sustentação em vez de tecnologias disruptivas e pode ser observada nas divulgações da empresa Finn Frogne A/S líder mundial em tecnologias de táxi. Os investimentos em tecnologias realizados pela indústria dos táxis empenharam-se em soluções para melhorar a comunicação, a forma de pagamento, a segurança dos veículos, a navegação no trânsito e a eficiência de combustível.

A otimização de call centers para facilitar o agendamento, relacionamento com o cliente, fornecer informações de trânsito e gerenciar os dados financeiros foi uma forma de melhorar a comunicação. Dentre as melhorias nos veículos, os taxistas investiram em navegadores GPS, taxímetros mais seguros, câmeras de segurança, impressoras de recibo e a tecnologia de conversão para o gás natural veicular. São tecnologias de sustentação, que não provocam inovação disruptiva, mas se caracterizam como investimentos lógicos e racionais.

$\mathrm{Na}$ indústria dos táxis é possível identificar a falta de observação de que as tecnologias podem avançar mais rápido que a demanda do mercado. Considerando a hipótese de que a demanda do mercado de táxis é o simples deslocamento na hora certa e no local certo de um ponto A para um ponto B, é possível concluir que as tecnologias de sustentação dessa indústria excederam essa demanda. O cliente do táxi não deseja esperar o ônibus ou se deslocar até o metrô. Sendo assim, é indiferente para o consumidor se o taxista está usando o melhor taxímetro ou se está economizando combustível com um sistema de gás natural. A demanda seria o deslocamento, e algumas das tecnologias de sustentação dos táxis não interferem especificamente nessa atividade.

O último direcionamento que caracteriza organizações que fracassam é a compreensão de que o investimento em tecnologias disruptivas não é uma decisão financeira racional.

A Uber Technologies Inc., até a data de redação deste artigo, não é uma companhia de capital aberto. $\mathrm{Na}$ primeira rodada de investimentos que se encerrou em 2010, a companhia Uber arrecadou $\$ 1.25$ milhões de dólares. Em 2010 a média de preço das licenças de táxi em Nova Iorque era entre 600 e 800 mil dólares. Em 18 de fevereiro de 2016, o site de compra e venda de licenças de táxis em Nova Iorque nycitycab.com registra a oferta de medallions (alvarás) sem restrições por até \$1.6 milhões. Em 19 de setembro de 2017, o maior preço registrado era de $\$ 600$ mil.

Esses valores apontam para a capacidade financeira que alguns taxistas ou detentores de licenças de táxi possuem ou possuíam e que potencialmente poderia ter sido investido em tecnologias disruptivas. A constatação é que as pessoas que investem em licenças de táxi possuem capital para investir em inovações disruptivas. O que não quer dizer, necessariamente, que os compradores de alvarás de táxis não investiram ou estão investindo em tecnologias disruptivas.

A identificação dos investimentos realizados pelos táxis tidos como problemáticos no contexto da teoria de Christensen (1997) objetiva exclusivamente a discussão de possíveis correlações para explicar os motivos da redução de seu valor de mercado.

O investimento em tecnologias disruptivas depende invariavelmente da sua identificação anterior, não é improvável que em meados de 2009, ou até poucos anos depois, as pessoas tivessem dúvidas sobre a capacidade de expansão da Uber ou sequer da possibilidade de surgimento de um novo mercado para o transporte de passageiros, tornando muitas das decisões de investir em tecnologias incrementais justificáveis para os motoristas.

Vale ressaltar ainda que a Uber Technologies Inc. somou um prejuízo de US\$1,27 bilhão no primeiro semestre de 2016 (NEWCOMER, 2016). Os valores cobrados pela empresa como parte do valor pago aos motoristas não estão sendo suficientes para cobrir os custos de manutenção da tecnologia que é oferecida. A expansão do mercado anterior à lucratividade também é um procedimento característico das tecnologias disruptivas.

Ainda com um cenário de fortalecimento desse mercado, a perspectiva futura continua a ser $\mathrm{o}$ investimento em tecnologias disruptivas só quq, dessa vez, direcionada aos veículos autônomos. Em tempo, a Uber fez a aquisição da empresa de veículos autônomos Otto em 2016, e já realizou os primeiros testes da tecnologia na cidade de Pittsburgh nos Estados Unidos (CHAFKIN 2016). 


\section{Discutindo a disrupção e a instabilidade}

Com base no esclarecimento sobre o ciclo econômico de Schumpeter foi possível observar, através do acelerado surgimento de aplicativos análogos ao Uber, o movimento de reestabelecimento do equilíbrio econômico, que é entendido como sucessor de um momento de instabilidade ou ruptura do ciclo.

Foi demonstrado que A Uberé uma inovação disruptiva sob todos os aspectos, as cinco possibilidades de novas combinações capazes de provocar a destruição criativa listadas na teoria de Schumpeter são observadas, sendo que, apenas uma nova combinação seria suficiente para criar a instabilidade.

A empresa Uber, através das possibilidades de escolha de veículos mais luxuosos, introduziu uma nova qualidade para o serviço de transporte de passageiros e, por meio de aplicativos em dispositivos móveis, uma nova forma de comercializar esse serviço. Um novo mercado, diferente daquele controlado pela posição de monopólio da indústria dos táxis, é aberto utilizando como fonte de oferta de serviços os veículos dos motoristas comuns.

O mercado dos táxis, até maio de 2015, não foi efetivamente prejudicado, conforme constatado na pesquisa de Esteves (2015). É a partir da verificação dos indicativos produzidos por Christensen (1997) que o fracasso da indústria dos táxis apresenta-se como uma possibilidade, os dados de 2015 sugerem a estabilidade, mas ressalta-se aqui a importância de pesquisas mais recentes para essa verificação.

O investimento em tecnologias de sustentação ao invés das tecnologias disruptivas foi observado nas variedades de tecnologias oferecidas pela empresa Finn Frogne, especializada no segmento de táxis, e que se autodenomina líder mundial em tecnologias para táxis. Todas as tecnologias oferecidas por essa empresa assumiam uma função de sustentação do modelo em vigor.

A falta de percepção de que as tecnologias podem avançar mais rápido do que a demanda do mercado ampara-se naquilo que foi identificado como as tecnologias que promoveram o avanço tecnológico do táxi: kit para conversão de gás natural veicular; melhores taxímetros; melhores centrais de atendimento. Tecnologias de sustentação que buscam proporcionar melhores serviços que os competidores, melhores margens de lucro, mas excedem a demanda do mercado por deslocamento.

O entendimento de que o investimento em tecnologias disruptivas não é uma decisão financeira racional é identificado a partir da verificação de onde os recursos financeiros da indústria podem estar sendo aplicados: a compra e venda de licenças ou alvarás. Sendo essa decisão, e não a compra de um veículo capaz de atender os requerimentos das empresas de transporte por aplicativos, uma decisão que possui uma data de expiração relacionada à sua lucratividade, segundo Christensen (1997).

Não se pode afirmar com perfeito e indiscutível conhecimento, que a indústria de táxi, como um todo, não está investindo nas inovações disruptivas. Esta pesquisa trata apenas de ponderar o investimento financeiro observado na empresa Uber e para a possibilidade de investimento diante do potencial identificado nas transações de compra e venda de alvarás em grandes metrópoles com Nova Iorque. A indústria de táxis investiu na atuação em aplicativos de dispositivos móveis, como o 99taxis e o Easytaxi para melhorar seus serviços e competir com o Uber.

\section{Considerações finais}

As contribuições do economista e cientista político Joseph Schumpeter, de onde surge a teoria da destruição criativa, por volta de 1942, e a pesquisa do professor de administração Clayton Christensen, de 1997, que criou a teoria da inovação disruptiva, alcançam uma importância significativa como paralelos comparativos para a compreensão das transformações sociais e econômicas provocadas pela empresa Uber.

A abordagem de Schumpeter coloca a tecnologia como elemento central do ciclo econômico, que no caso aqui estudado, aplicou-se de modo adequado. $\mathrm{O}$ valor social do serviço de transporte de passageiros é alterado com a inovação dos aplicativos de smartphone e a qualidade do serviço é motivada em algumas circunstâncias pelo próprio sistema de avaliação recíproca do aplicativo. Causalidade esta sugerida aqui para pesquisas futuras.

Este trabalho contribui para a literatura por oferecer uma investigação baseada na teoria schumpeteriana para entender os motivos que provocaram os conflitos entre motoristas Uber e taxistas. A apresentação da 
Uber no contexto de um modelo de negócio disruptivo também é uma consequência do que foi aqui exposto.

Listados por Schiavi e Behr (2017) em seu estudo bibliométrico, os aplicativos móveis recebem destaque nos trabalhos científicos sobre inovação disruptiva compondo as principais ocorrências de análise junto a tecnologias como o bluetooth, skype, dados em nuvem, impressão 3D, internet das coisas, PAS, uma tecnologia de comunicação sem fio e o comércio C2C. Este artigo soma-se assim aos trabalhos sobre tecnologias e inovações disruptivas que buscam investigar aplicativos e que provocam um impacto no mercado e consequentes reestruturações nos modelos de negócio.

Ao futuro, destaca-se a importância de estudos que procurem acompanhar os investimentos da Uber em novas tecnologias disruptivas como os carros autônomos, o que pode ser entendido como consequência do volume de serviços análogos surgidos após o seu lançamento e listados na tabela 1 deste artigo.

A observação dos conceitos de tecnologia disruptiva aplicados ao caso da empresa Uber em sua atuação no Brasil procurou esclarecer os motivos pelos quais esta tecnologia provocou a efetiva disrupção no mercado e sua instabilidade. O posterior conflito com os taxistas e a aspiração por sua regulamentação são consequências da instabilidade aqui estudada.

Sem a destruição criativa ou sem as tecnologias disruptivas, a sociedade não viveria no conforto proporcionado pelas inovações. Fazer mais com menos, criar melhores soluções, atender mais consumidores e satisfazer mais desejos e necessidades de forma criativa é o que impulsiona o mercado e promove as evoluções tecnológicas.

\section{Referências}

ADNER, Ron, When are technologies disruptive? A demand-based view of the emergence of competition. Strategic Management Journal, 2002. pp. 667-688.

\section{BARRO, Josh. Taxi Mogul, Filing Bankruptcy,} Sees Uber-Citibank Plot. 2015. Disponível em: <https://www.nytimes.com/2015/07/23/upshot/ taxi-mogul-filing-bankruptcy-sees-a-uber-citibankplot.html>. Acesso em: 19 set. 2017.
CHAFKIN, Max. Uber's First Self-Driving

Fleet Arrives in Pittsburgh This Month. 2016.

Disponível em: <https://www.bloomberg.com/ news/features/2016-08-18/uber-s-first-self-drivingfleet-arrives-in-pittsburgh-this-month-is06r7on>. Acesso em: 21 set. 2017.

\section{CHRISTENSEN, Clayton M. The Innovator's} Dilemma: When New Technologies Cause Great Firms to Fail. Boston, Massachusetts: Harvard Business School Press, 1997.

CHRISTENSEN, Clayton M.; RAYNOR, Michael E.. O Crescimento Pela Inovação: Como crescer de forma sustentada e reinventar o sucesso. São Paulo: Elsevier, 2003.

ESTEVES, Luiz Alberto. Rivalidade após entrada:: o impacto imediato do aplicativo Uber sobre as corridas de táxi porta-a-porta. Brasília: Departamento de Estudos Econômicos - Dee, 2015. Disponível em: < http://www.cade.gov.br/ upload/Rivalidade após entrada - o impacto imediato do aplicativo Uber sobre as corridas de táxi.pdf $>$. Acesso em: 18 fev. 2016.

GOOGLE. Uber taxi pesquisa google. 2017. Disponível em: <https://www.google.com.br/ search?hl=pt-BR\&tbm $=$ nws\&authuser $=0 \& \mathrm{q}$ $=$ uber + taxi\&oq $=$ uber+taxi\&gs_l=news-cc.3. .43j012j43i53.1654.2714.0.2932.9.7.0.2.2.0.163 $.612 .5 j 2.7 .0 . .0 .0 \ldots 1$ ac.1.YrLLFaxEv8Q\&gws_ $\mathrm{rd}=\mathrm{cr} \& \mathrm{dcr}=0 \& \mathrm{ei}=1 \mathrm{~B} 3 \mathrm{BWYXwIIWmwAT}{ }^{\prime} \mathrm{K}$ oAg >. Acesso em: 19 set. 2017.

NELSON, Richard R.; WINTER, Sidney G. An evolutionary theory of economic change. Cambridge: Harvard University Press, 1982. 437p.

\section{NEWCOMER, Eric. Uber Loses at Least $\$ 1.2$}

Billion in First Half of 2016. 2016. Disponível em: <https://www.bloomberg.com/news/ articles/2016-08-25/uber-loses-at-least-1-2-billionin-first-half-of-2016>. Acesso em: 21 set. 2017.

ROSENBERG, Nathan. Inside the black box: technology and economics. Cambridge: Cambridge University Press, 1982. 304p.

The direction of technological change.

Inducement mechanisms and focusing devices.

Economic Development and Cultural Change, v.18, n.1, p. 1-24, october 1969. 
SCHIAVI, Giovana S.; BEHR, Ariel. Modelos de negócios disruptivos: um estudo bibliométrico da produção científica disponível em bases de dados nacionais e internacionais. Conf-irm 2017 Proceedings. 19., p.1-16, jan. 2017.

SCHUMPETER, Joseph A. Teoria Do

Desenvolvimento Econômico: Uma Investigação Sobre Lucros, Capital, Crédito, Juro E O Ciclo Econômico. São Paulo: Editora Nova Cultural Ltda., 1997. Disponível em: <http://www.ufjf.br/ oliveira_junior/files/2009/06/s_Schumpeter_-_ Teoria_do_Desenvolvimento_Econômico_-_Uma_ Investigação_sobre_Lucros_Capital_Crédito_Juro_e_ Ciclo_Econômico.pdf>. Acesso em: 04 fev. 2016.

\section{Capitalism, Socialism And Democracy.}

New York: Taylor \& Francis E-library, 2003.

Disponível em: <http://digamo.free.fr/capisoc. pdf>. Acesso em: 05 fev. 2016.

SUSAN, Usha; CHANDRADAS, Vishnu.

Schumpeter theory of economic development. [estados Unidos]: Slideshare, 2012. 14 slides, color. Disponível em: <http://pt.slideshare.net/ vishnuchandradas/schumpeter-theory-of-economicdevelopment-11555141>. Acesso em: 11 fev. 2016.

UBER. Atrás do volante: Há pessoas como você, indo para mesma direção. Disponível em: $<$ https://www.uber.com/pt/>. Acesso em: 18 fev. 2016.

YU, Dan; HANG, Chang Chie. A reflective review of disruptive innovation theory. International Journal of Management Reviews. v. 12, 2010. p. 435-452. 